\title{
Exploring Pedagogical Leadership in Early Years \\ Education in Saudi Arabia
}

by

Lubna Alameen (Princess Noura University), Trevor Male (UCL Institute of Education) and loanna Palaiologou (Canterbury Educational Services)

[Published in School Leadership and Management, 35(), 121-139.]

[To cite this article: Alameen, L., Male, T. and Palaiologou, I. (2015) Exploring Pedagogical Leadership in Early Years Education in Saudi Arabia. School Leadership and Management, (35:2), 121-139. DOI: 10.1080/13632434.2014.992773]

To link to this article: http://dx.doi.org/10.1080/13632434.2014.992773

\begin{abstract}
The empirical research for this paper was undertaken with leaders of early years setting in the Kingdom of Saudi Arabia (KSA). The investigation sought to establish to what extent it was possible to behave in line with the concept of pedagogical leadership in the twenty first century in an Arab Muslim Monarchy, dominated by Islam, where directive leadership and control by the state has been the traditional norm. Education in KSA is now subject to reform, however, with leadership roles and responsibilities becoming a key issue and the early years sector being one of the major targets for development.
\end{abstract}

\section{Introduction}

The concept of leadership in education, and particularly in the pre-school sector, is contentious with most constructs proposed for adoption arguably being inadequately justified in the reality of everyday life. In most instances practitioners who are in formal leadership positions are confined in their range of potential actions by national policies and the local context, including the culture of the educational setting for which they are accountable. 
This has certainly been the case in the Kingdom of Saudi Arabia where, until recently, there has been centralised control of education, mainly through government ministries, which has left little room for manoeuvre for those in formal leadership roles within schools and early years settings. In the investigation we report here, which is based on empirical research within the kingdom, we seek to establish to what extent it is possible to exercise any local leadership behaviour and, in particular, to behave in line with the concept of pedagogical leadership in the twenty-first century in an Arab Muslim Monarchy, dominated by Islam, where directive leadership and control by the state has been the traditional norm. Education in KSA is now subject to reform, however, with leadership roles and responsibilities becoming a key issue and the early years sector being one of the major targets for development. Consequently central government has now established greater opportunities for local decision making in order to maximise the policy intentions signalled in the development plan for education (Tatweer, 2010), which was confirmed in 2014 (Ministry of Education, 2014).

\section{Constructs of Educational Leadership}

Sergiovanni (1992) suggested that for the last half of the twentieth century formal leadership in education settings was considered to be about two things: trying to figure out what needs to be done to make the organisation work and work well and trying to figure out how to get people to do these things. He labelled this the 'Expect and Inspect' model which, on close examination, features only one aspect of leadership behaviour - the ability 
to keep up morale through the use of good human relations (see Table 1). This can be considered as a management rather than leadership model which was subsequently labelled 'managerial leadership' (Leithwood, Jantzi and Steinbach, 1999).

- State your objectives

- Decide what needs to be done to achieve these objectives

- Translate these work objectives into role expectations

- Communicate these expectations

- Provide the necessary training

- Put the people to work

- Monitor the work

- Make corrections when needed

- Throughout, practice human relationships leadership, to keep morale up

Table 1 - Managerial Leadership (Leithwood, Jantzi and Steinbach, 1999)

Conversely leadership should be about decision making rather than the delivery of decisions that have been made, a process perhaps best described by Covey (1992: 101):

Management is efficiency in climbing the ladder of success; leadership determines whether the ladder is leaning against the right wall.

In this sense leadership is perceived as "the ability to motivate, influence, and enable individuals to contribute to the objectives of organisation of which they are members" (House et al., 2004: xxxi). These two definitions agree in viewing leadership as a process that entails (1) general influencing (2) influencing others, individuals or groups, not only for their own sake, but for a common and shared goal, and (3) influencing the aims and purposes to 
be achieved. A common theme in such understanding is that leadership involves the ability or capacity to gain results from people through persuasion, to achieve a shared purpose (Mir, 2010).

Consequently theories of leadership have evolved through constructs based on transactional or transformational behaviours which encourage the sharing of leadership, as it is generally considered that it would be rare for a single person to exercise all the leadership behaviours required to successfully run an organisation (e.g. Harris, 2004; West-Burnham, 2004). A Transactional Leadership style relies on a system of rewards and punishment that work as key motivators whereby leaders "approach followers with a view to exchange or barter" (Wright, 2007: 24). In contrast, in Transformational Leadership, a common goal is supported by engaging one person with another in a relationship that raises their level of motivation and morality. The concept of Transformational Leadership first emerged with the work of Burns who stated that such a leader focuses on change, therefore transforming others within the organization, and "looks for potential motives in followers and seeks to satisfy higher needs, and engages the full person of the follower" (Burns, 1978). Such leaders work as role models, maintain optimism, mobilize commitment and show concern for followers' needs and for organisational development (Bass, 1998).

In applying this to education, and consistent with evidence of benefit from collaborative approaches, it was Sergiovanni who concluded there will need to be many leaders in an excellent organisation. Highly successful leaders, he claimed, recognise the importance of 'leadership density' which refers to 
"the extent which leadership roles are shared and the extent to which leadership is broadly exercised" (Sergiovanni, 1987: 22).

\section{Leadership in Education}

Thus a conflict can be detected, we suggest, between the 'ideal' world of theory and the 'real' world of practice. Much emphasis has been placed on collective and distributive approaches to leadership in educational settings without there always being a necessary recognition of everyday life. In early years settings in England, for example, there is a genuine lack of clarity as to the locus of leadership accountability within a context of legislation (the Early Years Foundation Stage), shared responsibility for children between agencies and the ownership of early years settings (Male, 2013). The environment for individuals with formal leadership responsibility thus can lead easily to a situation where managerial activity is more likely. Similarly the central directive leadership and policy making seen within the Kingdom of Saudi Arabia could lead to the situation where formal leaders in educational settings do not see a decision making role for themselves and revert, instead, to managerial activity.

Constructs of education leadership that have emerged, however, attempt to highlight behaviours which promote student learning (as well as managerial activity), although many such approaches appear more concerned with student outcomes rather than their experiences. Two such examples are Instructional Leadership and Learner-Centred Leadership (which is an extension of the former). Instructional Leaders were those who had 
extended their role beyond managerial tasks in order to affect the quality of teacher performance in the classroom. These pioneers, mainly in the USA, were described as "strong, directive, goal-oriented leaders" and "culture builders" who frequently had "turned their school around" and sustained an "academic press ... that fostered high expectations and standards for students, as well as for teachers" (Hallinger, 2005: 3). As governments and school systems pressed for higher levels of student achievement the construct of instructional leadership was developed further through the 1990s in school effectiveness and improvement programmes. By this time instructional leadership was seen to be collective in practice, rather than individual, and was frequently re-named as 'learning-centred' or 'learnercentred' leadership as it was adopted internationally (see, for example, Southworth, 2002). There is now a common core to these models, each of which recognised that the direct engagement of formal leaders in student learning was less instrumental in improving and enhancing student attainment than the impact that could be achieved through indirect activity. In other words ostensibly there was encouragement for the actions of formal leaders in educational settings to be transformational.

Learning-centred leaders of schools tended, however, to focus their efforts on the "academic press" and to "build data-driven professional communities that hold all individuals accountable for student learning and instructional improvement" (Mazzeo, 2003: 2). Leadership in practice tended to become an exercise of staffing the teaching programme, providing teaching support, monitoring school activity, and buffering staff against distractions from their 
work (Leithwood et al., 2006). Consequently we sought to re-conceptualise Pedagogical Leadership, which has often been promulgated as a desirable approach for education, as such a style appears to focus on the fundamental process of supporting learning (Male and Palaiologou, 2012). We argued that pedagogical leadership is something more than supporting teaching and learning and carries with it an expectation that actions should not be predetermined, but relevant to situation and context. Thus we describe leadership as praxis for which, we argued, there can be no right way of acting or practice, instead actions should be appropriate to a particular situation (Male, 2006). Consequently we argued that pedagogy in the twenty-first century should be about offering the capacity to learners to challenge existing knowledge and to develop the skills to deal with an unspecified future. In such an environment pedagogical leadership is an ethical approach which respects values and does not engage in any project that will only benefit the individual, but instead looks after the ecology of the community.

We concluded, therefore, that pedagogy is a triangulated concept that is concerned with theory, practice and a set of social axes. Pedagogy is thus (see Figure 1) the creation of learning environments in which the centrality of interactions and relationships among learners, teachers, family and community interact with external elements in order to jointly construct knowledge (Male and Palaiologou, 2012: 7). This understanding enables us to identify aspects of the environment that are pedagogical (social) axes: 
- Internal axes (values, beliefs, culture, religion, customs and local economy), and

- External axes (societal values, global economy, mass media, social networking, information communication technologies, national curriculum, the 'academic press' of student test scores).

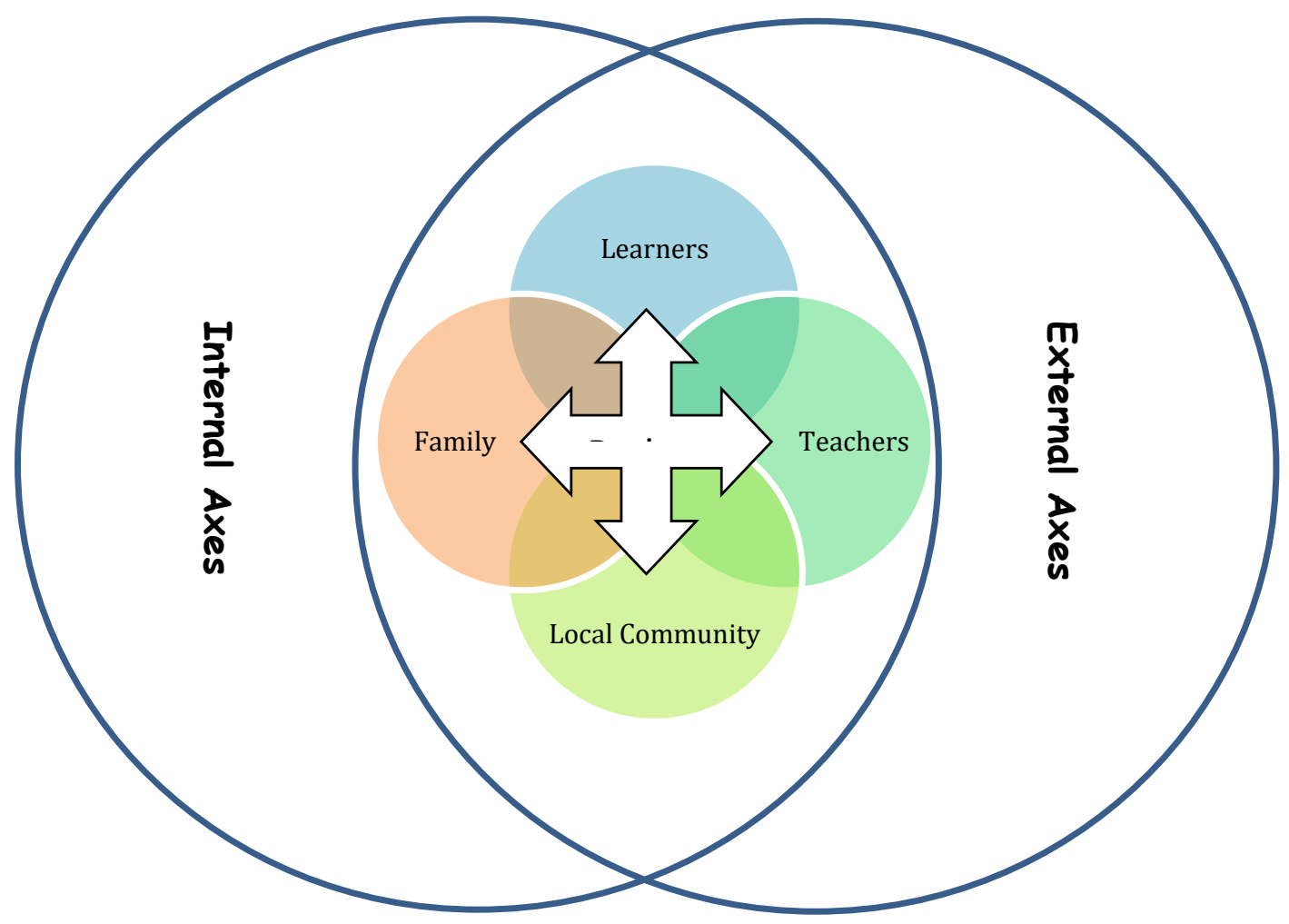

Figure 1: The Relationship between Pedagogy and Social Axes (Male and Palaiologou, 2012)

In that sense leadership becomes praxis that goes beyond practice within the immediacy of the educational setting and has, instead, a key focus on the threefold development of:

- interactions in the ecology of the community;

- activities with all participants;

- the construction of knowledge using all available resources such as technology.

Consequently Pedagogical Leadership builds on previous work in the field of education through seeking to take account of personal and local learning 
needs as well those relating to organisational and systemic (national) needs. Pedagogical leadership thus extends the notion of learner-centred leadership (which itself was a much more personalised approach than typically employed in instructional/learning-centred approaches) to encompass the ecology of the community as well as the individual learner.

\section{The Saudi Context}

The research reported in this study was undertaken in Saudi Arabia, an Arab Muslim Monarchy dominated by Islam because it is the heartland of Islam and the guardian of the two holy mosques. Saudi constitution and law are based on the Quran (holy book) and Sharia (Islamic law), overlays which mean religion permeates every part of life. Formal school-based education is segregated within the kingdom except in pre-primary education, which includes kindergartens for children aged three to six, which Al-Jadidi (2012) reports are attended in three levels according to their age (Kg1, Kg2 and Kg3). There are two types of kindergartens: private (local and international) and public, with both under the supervision of the Ministry of Education (Samadi and Murowa, 2001; Alsunbul et al., 2008). Whilst attendance at pre-school is not compulsory, many people believe it is essential in their children's journey of life (Ministry of Higher Education, 2010) and the Ministry of Education is reported to be willing to pay fees for parents whose children cannot find a place in a publicly funded kindergarten (Al-Thumairi, 2014). This is the only stage of education where enrolment is not gender segregated and, for cultural reasons, all EYE leaders, teachers and staff are female. As indicated above, however, Saudi Arabian education is now going 
through large scale reform in which leadership roles and responsibilities have become a key issue. EYE is one of the targets for development with a substantial budget having been allocated for training, buildings, policies and curriculum (Tatweer, 2010). Despite the establishment of a holding company, Tatweer Education, to take direct responsibility for the implementation of the plan there has been limited progress with implementation resulting in a change in 2014 to the management structure and an increase of overall budget.

The context is significant when exploring the ways in which formal leaders in Saudi Arabia are able to operate as most decision making, particularly in policy terms, has remained centralised and culturally constrained. Theories emanating from other cultural settings, particularly those found in 'Western' countries, thus need to be moderated in relation to the local context of Saudi Arabia. Traditionally government in the kingdom has been deterministic and prescriptive in nature, which reduces the capacity for decision making at the local or institutional level. Indeed within the capital city of Riyadh, where the research for this article took place, local social norms are more conservative than in some other parts of the country, thus ostensibly leaving little room for those charged with formal leadership of organisations, such as heads of early years settings, to do things differently. In other words it will be unusual to see decision making taking place at organisational level within the city. Consequently any indication of local decision making would be considered as significant in terms of the ability to exercise aspects of pedagogical leadership. 


\section{Pedagogical Leadership in Early Years Education}

As indicated above there has been evolvement in leadership approaches in education with past perspectives being reanalysed and novel concepts being introduced (Mir, 2010). In early years education it is noted that the quality of the educational organisations are highly influenced by the quality of leadership and management (Rood, 2006; Bush, 2011; Ang, 2011). Leadership in early years education, it is suggested, demands "a mature understanding of children and families" (Ang, 2011: 298). Others link distributed leadership, where leadership roles and responsibilities are shared and distributed among staff (Harris, 2004), with pedagogical leadership, where leaders are responsible for creating a learning community, where distributed responsibilities take place among children, parents, teachers, and the community (Heikka and Waniganayake, 2011).

Pedagogical leadership in EYE thus has no agreed definition as yet and appears to be a very recent concept with "limited theoretical advancement in writing about pedagogical leadership in early childhood education" (Heikka and Waniganayake (2011: 501). An emerging view, however, is responsibility of the formal leader in the educational setting to facilitate this processes of teaching, learning and community engagement in order to ensure that children's needs and interests are served (Sergiovanni, 1998). Heikka and Waniganayake (2011: 507) perceive pedagogical leadership, therefore, as "taking responsibility to ensure that practices are appropriate for children". Accordingly, it is argued, that through pedagogical leadership innovation and creativity in teaching is fostered (Webb, 2005). Pedagogical 
leadership in these circumstances is thus concerned with the professional development of staff, recognition of opportunities for learning for students and teachers and creating a learning community, the way that knowledge is generated and shared among the staff as well as decision-making among each other (Heikka and Waniganayake, 2011). Moreover, it offers a holistic approach to learning, because "the pedagogical leader sets out to address the whole child" (Moss, 2006: 32).

Pedagogical leadership not only invites teachers to make decisions in their classrooms as advocated in teacher leadership (Emira, 2010), therefore, but also encourages teachers' capacity by inviting them to participate in organisational decision-making including the broader community (Heikka and Waniganayake, 2011). Pedagogical leadership in early years education thus entails encouraging teachers to lead while linking school and home learning (Heikka and Waniganayake, 2011) and seeking "productive and synergistic relationships" between school and community to enhance learning through recognition of the importance of learners' context and culture (Male and Palaiologou, 2012: 6). Here again we can see the challenge presented by the cultural context where arguably the state has been more instrumental than parents in shaping decision making at the institutional level. The engagement of parents by teachers as suggested above could thus be considered as innovatory practice in Saudi Arabia.

Because relationships among learners, staff, community, parents and government are significant, Fullan (2001: 15) states that "leaders must be 
consummate relationship builders with diverse people and groups". A trusting and open atmosphere where experiences, practices and knowledge are shared, cooperative and collaborative work take place, and members are constantly exchanging resources with unconditional access, should be considered (Male and Palaiologou, 2012). A body of literature asserts that the nature of early years education requires building such relationships, especially with families (Aubrey, 2007; Roberts, 2011; Hughes and Read, 2012).

The research reported here seeks, therefore, to examine the behaviours of a number of innovative leaders in early years settings within the Kingdom of Saudi Arabia in order to discover to what extent they have been able to subscribe to pedagogical leadership approaches.

\section{Methodology}

The research team consisted of a native Saudi Arabian, a lecturer in Education employed by a university based in Riyadh, and two academics from the English university hosting the doctoral study of the lead researcher. Both English academics has extensive experience of working with research students from the Kingdom of Saudi Arabia and had each spent time in the country as visiting lecturers prior to this research project. In addition, they had been responsible for determining the construct of pedagogical leadership used in this investigation. 
The investigation reported here employed an interpretive inductive approach and adopted qualitative methods. Such an approach is appropriate when seeking in-depth understanding of participants' perspectives and to discover the common issues described related to their practical experiences (Bryman, 2008). Consequently flexibility to extract as much information as possible from the participants was needed. Five pilot interviews were conducted in English and in Arabic to assess the clarity of the interview questions and the questions revised accordingly. This piloting helped in identifying linguistic problems, and familiarised the first author and lead researcher with the semi-structured interview technique. The questions used in interviews were translated from English to Arabic and were checked by an independent translator in order to ensure the nature of the intended question was sustained when Arabic was used.

For the data reported here purposive sampling was adopted to choose early years' settings in the capital city of Saudi Arabia, Riyadh, and semistructured interviews were conducted with eight people recognised as leaders of the chosen settings. As indicated above the Saudi education system has certain characteristics due to its religion and culture, e.g. gender segregated, and all the early years workforce are female. Consequently, leaders considered in this research were female only with varied nationalities, years of experience and a mixture of public and private preschools (see Table 2). The principal criterion for selection of participants was to seek a balance between those who were responsible for public and private settings as other variables were either not readily available (e.g. 
length of service) or considered to be of lesser importance by the research team.

\begin{tabular}{|c|c|c|l|c|c|c|}
\hline & Position & Nationality & Gender & $\begin{array}{c}\text { Years of } \\
\text { experience }\end{array}$ & $\begin{array}{c}\text { School } \\
\text { program }\end{array}$ & School type \\
\hline AA & Leader & Saudi & Female & - & $\begin{array}{c}\text { Saudi } \\
\text { curriculum }\end{array}$ & Public \\
\hline LC & Leader & Saudi & Female & 14 & $\begin{array}{c}\text { Saudi } \\
\text { curriculum }\end{array}$ & Private \\
\hline LT & Leader & Saudi & Female & 5 & $\begin{array}{c}\text { Saudi } \\
\text { curriculum }\end{array}$ & Private \\
\hline NG & Leader & Syrian & Female & - & $\begin{array}{c}\text { Saudi } \\
\text { curriculum }\end{array}$ & Private \\
\hline NJ & Leader & Lebanese & Female & - & $\begin{array}{c}\text { Saudi } \\
\text { curriculum }\end{array}$ & Private \\
\hline LF & Leader & Saudi & Female & 9 & $\begin{array}{c}\text { IB + Saudi } \\
\text { curriculum }\end{array}$ & $\begin{array}{c}\text { Private non- } \\
\text { profitable }\end{array}$ \\
\hline LL & $\begin{array}{c}\text { Owner } \\
\text { and } \\
\text { leader }\end{array}$ & American & Female & 10 & $\begin{array}{c}\text { High } \\
\text { Scope }\end{array}$ & Private \\
international \\
\hline LI & $\begin{array}{c}\text { Leader } \\
\text { Pakistani }\end{array}$ & Female & 5 & $\begin{array}{c}\text { Standards } \\
\text { of } \\
\text { California }\end{array}$ & Private \\
international \\
\hline
\end{tabular}

Table 2 - Research participants

This enquiry adopted ethical procedures typically used in social sciences with participants being required to sign a letter of informed consent which guaranteed their safety and anonymity. In addition the Ministry of Higher Education in Riyadh provided a recommendation letter to allay participants' concerns. Prior to the start of the interviews the purpose of the enquiry was verbally explained to ensure participants understood what was being asked of them and to provide clarity of the study's objective. Openness and respect for the participants' rights and interests was maintained throughout the interview and participants were advised they were free to withdraw at any stage of the data collection. 
Four lines of enquiry were examined with the participants being asked to consider the following aspects of practice in their setting prior to us meeting with them and to discuss these during interview:

1. Establishing and sustaining the vision and mission of the setting;

2. How internal decision-making processes worked;

3. The relationships established to support learners;

4. Making use of appropriate technology in a digital age.

Recording of interviews is often difficult in these circumstances as there are concerns which are culturally based about the future use of such recordings which can lead to participants being reticent with their statements. Consequently only five of eight interviews were audio recorded (with permission) with additional field notes taken. Notes were also taken for the three unrecorded interviews and they were written up immediately after each interview to avoid data loss. There was no time-limit for each interview which took between 30 and 50 minutes. In order to ensure the validity of the data collected comparison and contrast between the participants' views was undertaken as they were under the same context; i.e. applying the same policy and under the supervision of the Ministry of Education.

For analysis of these interviews transcripts were coded and categorized according to themes using interpretive analysis. Data were further categorized through Nvivo software. Subsequently these data were also compared with the literature reviewed in this area. 


\section{Findings and Discussion}

1. Establishing and sustaining vision and mission:

It appeared that only three leaders had clearly identified and understood their school's vision and mission; another three did not clearly identify them; while the other two neither recognized the term 'vision' nor knew their school's vision and mission. One of those two was only familiar with the objectives and goals of the school, while the other mentioned a vision being written somewhere in the school documents. Furthermore, interviewees were confused between 'mission' and 'vision'. Despite the prior discussion about the importance of understanding the institution's vision and mission, this lack of recognition supports Gill's (2006) claim that some people in organizations do not take these statements seriously or know the purpose of the organisation.

In terms of participation in setting the vision and mission, seven respondents indicated that they were not involved in this. The eighth claimed that the vision was set through collaboration of school staff, parents and the principal. Of the first seven respondents, three of them said the vision was realised in that way because they are part of a bigger group of schools, and the top management of the group (usually the owners) developed the vision and mission of the whole institution. One of these three schools had a School Council which managed the school, because the owner was a private nonprofitable organization, while the other two private pre-schools had independent leaders who reported to the owner. However, the eighth respondent was different because she was both the owner and the principal 
of the school. She declared her beliefs in listening to parents, children, staff and involving everyone in developing the school's vision and mission.

The importance of the vision and mission was highlighted by two respondents, who linked the success of the school with having an announced vision and mission that everyone believes in and understands it. According to LF:

My vision is my school vision, I believe it is announced, everyone has to know it. So when you walk into a place, you need to shape everything based on its vision and mission. I should believe in it. I think the person should not accept the job if he does not believe in its vision and mission, it is not a job, humans have to have targets and goals, not working for profits. Passion is very important at work. The passionate one who believes in what he is doing and enjoys it, will be successful in his work, whether it is a leader or teacher or others (LF).

Moreover, another respondent emphasized the importance of staff buying in to the vision and mission:

I do not believe in forcing things on people, I try to culture it. Culture means you cultivate it in the society, teachers, staff, parents or whosoever. You have to be the one to carry it to make others feel that they would like to have it as well. So, it is the way we market it [...] I always show them with an attitude that this is professional, this is positive and this is required. (LI).

Thus, to some leaders, the vision and mission of the school are significant. This echoes Kantabutra (2009) argument that people's belief in the organisation's vision and mission contributes to its success, whereby staff become self-motivated to achieve its goals and targets. Moreover, it can be seen that establishing a school culture and creating clear core values by having a clear vision shapes the leaders' and staff behaviours. This is what 
Male and Palaiologou (2012) suggest as internal axes that shape pedagogical leadership.

\section{How internal decision-making processes worked}

Three different levels of decision-making were highlighted by LF, LI and LT:

- strategic decisions;

- operational decisions;

- class decisions.

The remaining five interviewees agreed on two levels of decisions, those related to the classroom and others to the pre-school in general.

For the first three, who were part of a bigger group of schools, only one leader, LF, was involved in strategic decisions, which are made collaboratively with all school principals. The remaining two, $L T$ and $L I$, reported that strategic decisions were made by the owner and the top management of the schools.

Operational decisions, as indicated by those three leaders, were made differently. LT claimed that she and the teachers made such decisions collaboratively. LI added that parents take part of the decision-making with the staff and the leader. LF added an external social worker who considered, with the principal, teachers, and parents, participated in the decision making in order to ensure all decisions meet children's need.

Regarding decisions made within the classroom, LF and LG, argued that teachers are flexible and independent in making decisions. The other two, 
LC and LT, agreed that decisions within the class were limited because of the involvement of several parties, including the superintendent and the principal, who are guided by the policy and the curriculum.

The fourth and fifth principals, LL and LC, agreed that parents and teachers are involved, but decisions were made differently. LL applies a voting approach, where the majority decide while LC applies a consulting approach, whereby the leader decides after listing to the participants' views. LI illustrated how she managed to involve parents and teachers in decisionmaking. She explained that options, for instance, for 'after school activity' were given by her and the decision was taken by them. She declared "in the end [...] myself and them both lie in the same table, we agree". Despite allowing parents and teachers to contribute in decision-making, she still controls the process by drawing certain boundaries with her options so it is still in the end her decision. However, she believes that:

This is the best way to run an organization. Give them options, they would never be able to say no and they would never say that you left us alone [...] they want to do it and they find it more respectful in this way, that I gave them a way to do things that I am supposed to do. (LI)

Such approaches to decision-making, appear to be consistent with Aubrey's (2007) view that leaders' role is making strategic decisions, while the team can make operational decisions, whereby a sense of collaboration is developed. Nevertheless, the evidence in this research of different types of decision-making may reflect Rodd's view, that decision-making style depends on the leader's characteristics, the professionals involved, as well 
as the nature of the decision being taken (Rodd, 2006). Nevertheless, it is important that staff are motivated and a sense of collaboration is encouraged to contribute to the organization, as $\mathrm{LI}$ illustrated, and further concern about the community, children and their families would be beneficial, as discussed in the next section.

\section{The relationships established to support learners}

All respondents agreed on having relationships with two stakeholders, parents and teachers, was vital in order to support learners. All the leaders agreed on the importance of involving parents in their children's education, and reported frequent contact with parents, mainly mothers, via conferences, letters, and creating a portfolio for each child to record their progress.

Three interviewees valued both parents being part of their children's education. For example, LF invites fathers and mothers, with teachers' participation, to sports day where the father and child do something together and the mother is cheering. Parents also were invited to activities such as a puppet show or a story telling by a local author. LT invites fathers to be shown round the school by their children who can then point out their own work, in the presence of a male teacher from the another part of the school. Female teachers were in contact with fathers only by phone, if needed. In contrast, LI clearly stated that fathers are not involved in her setting, as it is segregated: however, email contacts were welcomed. 
Examples mentioned by $\mathrm{LT}$ and $\mathrm{LI}$ reflect some social and religious values of their community in such as gender segregation and limited communication with males. Such societal and religious values can be considered as external and internal pedagogical axes that influence the leader's behaviours (Male and Palaiologou, 2013). The example provided by LF, however, of including both genders reflects her own beliefs, as an internal axis, and the influence of the promoted programme - the International Baccalaureate Primary Years (IB) - as an external axis. Despite the differences between these leaders on sustaining equilibrium between both axes, building such relationship with the local community demonstrates their concern to take account of "the ecology of their community" for the learners' locality. LL's pre-school was quite distinctive, however, in that the principal created an open door policy. According to her,

Mums and dads can come anytime to visit the school, we don't shut them out. We do assembly every morning where mums are able to join in. We do coffee mornings for the mothers every month to discuss topics so, they can understand what exactly we are doing and what their children are doing and are better informed. (LL)

It can be seen here how the principal not only encourages parents to be in contact with the school by allowing them to visit at any time, but also promotes knowledge-sharing by offering workshops and discussion sessions. Similarly, the other three settings also offer information to parents, in such as training courses on IB, and seminars and symposiums about topics like protecting children from sexual abuse. 
In line with Male and Palaiologou (2012) and Fullan's (2001) arguments about school, home and community relationship, the respondents' relationships can be seen as synergistic and productive because parents seem to be part of the school community, as efforts have been made to share knowledge in order to support the learners. Nevertheless, LC mentioned that despite the school's attempts to reach every child's parents, not all of them are willing to be engaged with the school community. These are what Jones and Pound (2008) called 'hard-to-reach parents' which Jones et al. (2005) suggested may be for reasons such as health difficulties or prior negative experience. In this case, however, LC attributed it to parents' work responsibilities.

Also, it seems that religious and cultural values that influence the school relationships with parents depend on the leaders' values and beliefs, as fathers' presence and full engagement with the school were encouraged more by some leaders, LL and LF, than others, LT and LI. Here it can be argued that the internal pedagogical axes such as leaders' beliefs, values and religion are the key in driving the external axes such as social communication with the community.

Another challenge while communicating with parents that LF explained is her role in alleviating parents's anxiety about the IB programme as parents believe that traditional teaching and learning by books are needed, which is entirely different from the IB programme: 
The IB is very flexible; it is not based on curriculum. The biggest and the most challenge on this is to persuade the parents that there are no books to study from. As you know our education is stuck in the given area, having books to study from and then exams. In contrast, the IB is completely different concept and is based on teaching children how to search and how to get information (LF).

Jones and Pound (2008) claim that such unfamiliarity with the school system by parents, because they have been educated in a different way, places stress on their children. Therefore, involving and educating parents is important. Furthermore, parents' requirements when placing such pressure on the school can be considered as an external axis that influences the leader's behaviour. Nevertheless, as LF recognises the learners' benefit, she focused on raising the community's awareness to shift from traditional teaching and learning.

Teachers were seen as a key part of developing relationships with parents and learners; as all schools agreed on the importance of their professional development, participation and involvement within the school community. According to LL,

Every week they have a grade meeting and I have an open door policy. If they need to see me they can come and talk to me anytime. So, they are very much involved and at the end it is a shared decision, what we felt is the majority.

LC considers the teacher as the most important party in the school community as she implements ideas taken from others, such as the owner, principal, parents, and the social worker, in a manner that is appropriate to the child's locality. She believes, therefore, that supporting teachers personally and professionally is a key aspect in the success of the school. Similarly, LI while discussing the 'after school activity' decision-making 
explained, "My staff comes first because they are the ones who will handle it, I am not running it, I am just controlling it"; thus, their views and ideas were valued. Moreover, LC, LF and LL agreed on the importance of developing teachers professionally by offering them developmental courses, where exchanging and sharing of ideas and resources take place.

For instance, LF stated that:

There are certain trainings in IB depending on the module we give so, for example, we have training for the PE teachers who are sent to Dubai, Beirut or Switzerland sometimes. Similarly we have an IB coordinator, so we send her. All of them go to gain knowledge, skills and how to apply them in their specialist modules (LF).

Developing such shared understanding fits well with Lunn and Bishop's (2002) view that such a shared vision is the meaning of pedagogical leadership. Equally, Siraj-Blatchford and Manni (2007: 12) linked 'effective leadership practice' with effective collaboration and communication among each other in order to support learners. Building such home-school relationships to support the learner would enhance children's learning and development. In this regard, LF mentioned that:

Usually children learn more when they feel that there is a very strong link between the school and home [...] it helps children take it more seriously. (LF)

Therefore, supporting learners and building relationships with them were also seen as important, as four respondents agreed. Children were involved in various activities to support their learning and development. For instance, LC adopts programmes and provides visits to exhibitions according to children's developmental needs and interests. Besides, 'project based 
learning' takes place in Ll's preschool, where children are encouraged to participate actively and gain "hands on" experience. This leader brought her prior learning experience to the school, as explained:

I think when you put your knowledge to the test, into modelling that a school's road is to make a better citizen and a lifelong learner. So, that is how you give them confidence. (LI)

LL asserted the importance of bonding with pupils, saying:

I make sure that I am out there at the door greeting the children every morning, they bond with me as well as with their teachers, they come and give me a hug and talk to me, and when they have a problem they just open my door and walk in. So, I am there from the small things to the big things. (LL)

LL was the only one who explained her direct relationship with her children, whereas other leaders explained the efforts they were making for children in their schools. This could be justified as that LL is the owner and the principal of the school and has developed her experience and education in Western society. Such a trusting and open atmosphere affects learners positively as their confidence is built. She described the programme adopted in her school as child-directed, High Scope, which puts the child at its heart. She stated, "The child has the biggest say so, they are the biggest stakeholders" and emphasized the importance of collaborative work to encourage optimum learning.

All respondents saw close relationships with learners, teachers and parents as significant. Similarly, The Effective Provision of Pre-school Education project (EPPE) reports that "the excellent settings shared child-related information between parents and staff, and parents were often involved in 
decision making about their child's learning programme" (Sylva et al., 2004: 37).

Another relationship that three respondents, LC, LT and LF highlighted is with the government, specifically the Ministry of Education. In this regard, it was found that those schools that adopt the Saudi curriculum have better relationships with the Ministry of Education than others. As LT and LC described, not only were their programmes evaluated by a superintendent, but also mutual visits and events for developing and enhancing teachers' professionalism were organised. These events were specially planned to exchange experiences and resources with leaders and teachers from other local pre-schools. Nevertheless, principals in settings were perceived as "day-to-day managers", because they have limited control on the quality of learning and teaching, as it is the responsibility of the superintendent. Thus, the behaviours of leaders in these two settings seem to be closer to instructional leadership than pedagogical leadership.

Lastly, the relationship with the local community was a key relation in three schools. For example, LF invited an author to launch her latest books and provide each group of children with a reading of one of her stories and then met the parents to display her collections. Other given examples were liaison with hospitals, police, embassies and dentists where children are taken on organised visits. Another respondent, LL highlighted the existence of informal relationships with professionals, vendors and educational organizations in the USA, from which they try to learn about new methods 
of learning, technologies, and programmes and adopt an American system of learning. In this way pedagogical practice is fostered through exchange of teaching resources and diversification of teaching strategies (Young and Lucas, 1999).

Leadership and the administrative system would not work effectively without collaborative and cooperative efforts (Heikka and Waniganayake, 2011; Hughes and Read, 2012). Thus, building good relationships within the school community is important, as discussed. Accordingly, LC believes that:

As a leader, you have to be aware of and care about every little person in your organization, no matter who is it, the cleaner, cooker, teacher, child or whosoever. [...] The early years setting I always call 'family'. There is no way the leader, even if she is highly professional and qualified, can do everything alone. As a human, see how God created for you two hands and ten fingers, distributed, every part has its own job, you cannot say 'With my eye I will do everything'. No way. This is exactly the same as the administrative system [...] I always say to the teacher you are the most important one here. You are the one who takes from me, the owner, and everyone else to put it into practice. (LC)

Such discussion illustrates this leader's beliefs and values, regarding the importance of building relationships with and caring about every party in the school, as well as working collaboratively, as the path to a successful organization.

Although developing synergistic and productive relationships with the school and the local community is vital to support learners, a stimulating environment, is another important factor. As LF argued, 
There are different ways and programmes for learning but in the end if you create the appropriate environment for children in this age, they will learn, whether it was at school or at home, he will learn. What you are trying to do in the school is to determine what the child will learn, the amount given to him, and put targets ... this is what drives children into learning certain skills.

Not only does she point out the importance of creating an effective learning environment for children of this age, but also knows what they need to learn thus creating an environment "which will provide the recognition and the representation of knowledge", which is "inseparable from the community ecology" (Male and Palaiologou, 2012: 7-8).

\section{Making use of appropriate technology in a digital age}

Four leaders, LF, LI, LC and LL explained how websites were utilized for communication with various stakeholders such as students, parents, teachers and the local community. Three leaders revealed that social networking, mainly Facebook, was used for such communication. Only two used emails as a tool for communication with others. LF indicated that her school had a virtual online system to which parents, teachers, students and the principal have access, through which, for example, weekly reports could be generated. She also mentioned that they have an online curriculum centre $(\mathrm{OCC})$, based on the $\mathrm{IB}$, whereby teachers are provided with guidelines, ideas and examples if they struggle in particular concepts. Such use of technology is consistent with the argument that using technology in education can produce positive outcomes, through opportunities to exchange teaching ideas that will result in more effective teaching (Baytak et al., 2011). Equally, LL explained that programs and applications such as 
phonic games were provided to be installed in children's IPads to support their learning. Nevertheless, she stated:

For the younger ones we do not push that too much because they need to experience nature and natural things... we do encourage and send out websites, but at the same time we ask parents to minimise the use of technology with the little ones. (LL)

One interviewee, LI, stressed that using emails and Facebook improves communication with parents. The majority of the staff were English speakers and had difficulty with non-English speaking parents, but technology helped them to send Arabic messages for them and also parents could translate any English communication. Besides, LI stated other factors were needed to bridge the gap:

There is basically no gap right now. In the beginning because of the language barrier, there was a big gap and we came up with the idea of after school activities and remedial classes such as supplementary course in English during school hours. (LI).

Technology not only counters the language communication barrier it is also, according to Coklar (2012), a very powerful tool in interactions between people from different backgrounds. Similarly, LT argued that there is no gap now between home and school because we live in an open world and children are aware of everything, nevertheless, "it is our role to support the child's cognitive development to use the technology in a way that supports his learning positively".

Earle (2002) concluded that leadership, appropriate technological resources and professional development are among the factors that 
influence technology in education, and result in positive educational outcomes. This is part of what pedagogical leadership is concerned with.

\section{Summary discussion}

As indicated four lines of enquiry were established to ascertain whether there was evidence to support the idea that some leaders of early years settings in Saudi Arabia were able to engage in behaviours that corresponded to the construct of pedagogical leadership. The findings demonstrated that in terms of establishing and sustaining the vision and mission of the setting, there was evidence that showed formal leaders of each setting were corresponding their behaviour to internal pedagogical axes, rather than being solely driven by external agendas. In regard to internal decision-making it was common for leaders in these settings was to consult with operational staff, whilst retaining responsibility for strategic decisions. The greatest amount of evidence accumulated through this study related, however, to the way in which relationships were established and sustained within the setting and with parents and the local community to support learners, with all respondents considering such relationships as being of great significance. Here leaders were creating synergy between learners, staff and parents in order to represent knowledge which was inseparable from the community ecology, although it was also evident that some parents who were still hard to reach. Nevertheless there were cases, for example, where fathers were encouraged to have full engagement with the staff of the setting, an outcome that can be considered as unusual in the 
context of the education of young children in the country. It was also evident that leaders were seeking to make use of appropriate technology in a digital age, an approach which corresponds to the construct of pedagogical leadership in the current century.

\section{Conclusion}

Results from this small-scale research show that a small number of formal leaders in the early years settings appear to practice the full role of leadership: they form the vision and mission, make all kinds of decisions without limitation and appear to be flexible in building relationships and freely involving others in the school's decision-making. In contrast, in most cases they appear to play only partial roles as pre-school leaders: they were seen to be managing the setting more than leading, probably as a result of being restricted by circumstances relating to external axes related to the school. It appears that the application of pedagogical leadership in pre-school settings in this study were influenced by factors such as the leaders' relationships with the school community, including learners, parents, teachers and others such as superintendents and social worker. The more these relationships were seen to be synergistic, the more the school was deemed to be effective with children's learning and development being fulfilled in the view of those we interviewed.

Moreover, the school programme in these settings was seen to highly influence the school community's mission to achieve their tasks and objectives, as well as their relationships with others. For example, those

settings which applied the IB or High Scope programme appeared to 
develop stronger relationships both within the setting and with the local community than others, while those adopting the Saudi curriculum appeared to have closer relationships with the government. Using technology in education such as websites and emails was shown to be bridging the gap between home and the setting, and to be developing relationships with parents and the community.

Thus it can be concluded, in line with Sergiovanni (1998), that it is "leaders [who] hold the responsibility to build pedagogical communities" where individuals within the school community are empowered and an extensive range of methods, materials and technologies are considered. This is the “epistemic nature of pedagogy" (Male and Palaiologou, 2012: 8).

Practitioners in early years settings are "well placed to advocate on behalf of children and families and take the lead in connecting home and school learning. This is pedagogical leadership in practice" (Heikka and Waniganayake, 2011: 507). To some extent, this is what we found some of the participants in this research are practising despite the nature of the external axes. These are encouraging findings, given the nature of the larger social system within the kingdom.

\section{References}

Al-Jadidi, N. (2012). The Professional Preparation, Knowledge and Beliefs of Kindergarten Teachers in Saudi Arabia. Doctoral thesis submitted to University of Exeter, UK.

Alsunbul, A., Alkhateeb, M., Metwaly, M. and Aljawad, N. (2008). Education System in the Kingdom of Saudi Arabia. Riyadh, Dar Alkheraiji Publisher. 
Al-Thumairi, A. (2014). State to Pay for Kindergarten Education. Arab News - Published 21 January, 2014, Available at: http://www.arabnews.com/news/512571 - accessed June 2014.

Ang, L. (2011). Leading and Managing in the Early Years: A Study of the Impact of a NCSL Programme on Children's Centre Leaders' Perceptions of Leadership and Practice. Educational Management Administration and Leadership, 40(3), 289-304.

Aubrey, C. (2007). Leading and Managing in the Early Years. London: Sage.

Bass, B. (1998) Transformational Leadership: Industrial, Military, and Educational Impact. New Jersey: Lawrence Erlbaum Associates.

Baytak, A., Tarman, B. and Ayas, C. (2011). Experiencing Technology Integration in Education: Children's Perceptions. International Electronic Journal of Elementary Education, 3(2), 139-151.

Bryman, A. (2008). Social Research Methods. Oxford: Oxford University Press.

Burns, J. (1978). Leadership. New York: Harper and Row.

Bush, T. (2011). Leading in the Early Years: Making a Difference. Educational Management Administration and Leadership, 40(3), 287-288.

Coklar, A. (2012). Evaluations of Students on Facebook as an Educational Environment. Turkish Online Journal of Qualitive Inquiry, 3(2), 42-53.

Covey, S. (1992). The Seven Habits of Highly Effective People. London: Simon and Schuster.

Earle, R. (2002). The Integration of Instructional Technology into Public Education: Promises and Challenges. 42(1). Available: http://www.asianvu.com/bookstoread/etp/earle.pdf - accessed May 2012.

Emira, M. (2010). Leading to Decide or Deciding to Lead? Understanding the Relationship Between Teacher Leadership and Decision making. Educational Management Administration and Leadership, 38, 591-612.

Fullan, M. (2001). Leading in a Culture of Change. San Francisco, JosseyBass.

Gill, R. (2006). Theory and Practice of Leadership, London: SAGE.

Hallinger, P. (2005) Instructional Leadership and the School Principal: A Passing Fancy that Refuses to Fade Away. Leadership and Policy in Schools, 4,1-20. 
Harris, A. (2004). Distributed Leadership and School Improvement: Leading or Misleading? Educational Management Administration and Leadership, 32(1), 11-24.

Heikka, J. and Waniganayake, M. (2011). Pedagogical Leadership from a Distributed Perspective Within the Context of Early Childhood Education. International Journal of Leadership in Education, 14 (4), 499-512.

House, R., Hanges, P., Javidan, M., Dorfman, P. and Gupta, V. (eds.), (2004). Culture, Leadership and Organizations: The Globe Study of 62 Societies. London: Sage.

Hughes, A. and Read, V. (2012). Building Positive Relationships with Parents of Young Children: A Guide to Effective Communication. London: Routledge

Jones, L., Browne, K., Aitken, S., Keating, I. and Hodson, E. (2005). Working with parents and carers. In L. Jones, R. Homes and J. Powell. (eds.) Early Childhood Studies: A Mutliprofessional Perspective. Maidenhead: Open University Press.

Jones, C. and Pound, L. (2008). Leadership and Management in the Early Years: from Principles to Practice, Buckingham: Open University Press.

Kantabutra, S. (2009). Toward a Behavioral Theory of Vision in Organizational Settings. Leadership and Organization Development Journal, 30, 319-337.

Leithwood, K., Jantzi, D. and Steinbach, R. (1999). Changing Leadership for Changing Times. Buckingham: Open University Press.

Leithwood, K., Day, C., Sammons, P., Harris, A. and Hopkins, D. (2006) Seven Strong Claims About Successful School Leadership. Nottingham: National College for School Leadership.

Lunn, P. and Bishop, A. (2002). Nursery Teachers as Leaders and Managers: A Pedagogical and Subsidiarity Model of Leadership. Research in Education, 67, 13-22.

Male, T. (2006). Being an Effective Headteacher. London: Paul Chapman.

Male, T. (2013). 'Leadership in the Early Years Foundation Stage'. In I.Palaiologou (Ed.) Early Years Foundation Stage (2/E). London: SAGE.

Male, T. and Palaiologou, I. (2012). Learning-centred Leadership or Pedagogical Leadership? An Alternative Approach to Leadership in Education Contexts. International Journal of Leadership in Education, 15 (1), 107-118. 
Mazzeo, C. (2003). Improving Teaching and Learning by Improving School Leadership. Washington DC: National Governors Association.

Ministry of Education (2014). The Ministry's Projects: Achievements of the MoE for 2011/12 financial year. [Online]. Available: https://www.moe.gov.sa/Arabic/Ministry/Pages/-Report-of-the-Ministry-ofEducation.aspx - accessed October 2014.

Ministry of Higher Education (2010). Education Levels. Available at: http://www.mohe.gov.sa/en/studyinside/aboutKSA/Pages/Education.aspx accessed June 2014.

Mir, A. (2010). Leadership in Islam. Journal of Leadership Studies, 4(3), 6972.

Moss, P. (2006). Structures, Understandings and Discourses: Possibilities for Re-envisioning the Early Childhood Worker. Contemporary Issues in Early Childhood, 7(1), 30-41.

Roberts, J. (2011). Trust and Early Years Childcare: Parents' Relationships with Private, State and Third Sector Providers in England. Journal of Social Policy, 1(1), 1-21.

Rodd, J. (2006). Leadership in Early Childhood: The Pathway to Professionalism. Buckingham: Open University Press.

Rood, J. (2006). Leadership in Early Childhood. London: Licensing Agency Limited.

Samadi, H. and Murowa, N. 2001. Handbook for the Child-centered Curriculum in Early Childhood Education. Riyadh: Ministry of Education.

Sergiovanni, T. (1987). 'The Theoretical Basis for Cultural Leadership' in L. Shieve and M. Schoenheit (Eds) Yearbook of the Association for Supervison and Curriculum Development. Alexandriam Va.: ACSA.

Sergiovanni, T. (1992). Moral leadership: Getting to the Heart of School Improvement. San Francisco: Josey-Bass.

Sergiovanni, T. (1998). Leadership as Pedagogy, Capital Development and School Effectiveness. International Journal of Leadership in Education, (1) 37-46.

Siraj-Blatchford, I. and Manni, L. (2007). Effective Leadership in the Early Years Sector: The ELEYS Study. London: Institute of Education.

Southworth, G. (2002) Instructional Leadership in Schools: Reflections and Empirical Evidence. School Leadership and Management, 22(1), 73-91. 
Sylva, K., Melhuish, E., Sammon, P., Siraj-Blatchford, I. and Taggart, B. (2004). The Effective Provision of Pre-School Education [EPPE] Project. London: DfES.

Tatweer (2010). King Abdullah bin Abdulaziz Public Education Development Project [Online]. Available: http://www.tatweer.edu.sa- accessed May 2012.

Webb, R. (2005). Leading Teaching and Learning in the Primary School: From 'Educative Leadership' to 'Pedagogical Leadership'. Educational Management Adminstration and Leadership, 33(1), 69-91.

West-Burnham, J. (2004) Building Leadership Capacity - Helping Leaders Learn. Nottingham: National College for School Leadership.

Wright, G. (2007). Leading Teaching and Learning: A Study of Transformational Leadership in Secondary Schools Facing Challenging Circumstances. Unpublished doctoral thesis: University of Hull.

Young, M. and Lucas, N. (1999). 'Pedagogy in Further Education: New Contexts, New Theories and New Possibilities' in P. Mortimore (Ed). Understanding Pedagogy and its Impact on Learning. London: Paul Chapman. 